\title{
Development and Verification of a Web Board Game Scale
}

\author{
Choongmeong Lee ${ }^{1}$, Sujin Bae', Jae Jun Nam¹, Jae Chan $\mathrm{Jin}^{2}$, and Doug Hyun Han ${ }^{1 凶}$ \\ ${ }^{1}$ Department of Psychiatry, Chung Ang University Hospital, Seoul, Republic of Korea \\ ${ }^{2}$ School of Social Welfare, Soongsil University, Seoul, Republic of Korea
}

\begin{abstract}
Objective Our previous study suggested that monitoring online board gamers may be an efficient approach to curb illegal gambling. We aimed to invent and validate a behavioral scale for assessing the risk of problematic web-based board gaming.

Methods The sample included 300 Korean adults, representing a response rate of $3.1 \%$. All participants were asked to complete a set of questionnaires, which included questions on demographic variables, patterns of online board gaming, and the web-based board game scale score. Exploratory factor analysis was performed to determine whether the items on the new behavioral scale would indicate a risk of pathologic web-based board gaming behavior.

Results The internal consistency of the 17 -item scale was high (Cronbach's $\alpha=0.89$ ). The test-retest reliability of the 17 -item scale in a randomly selected sample of 100 participants in 2 weeks was $\mathrm{r}=0.77(\mathrm{p}<0.001)$. The criterion-related validity based on a comparison of the total behavioral scale scores between the high-risk group and low-risk group was relatively high. The data obtained from the 300 participants were acceptable for a factor analysis. After removing 7 items from the 17-item scale, internal consistency (Cronbach's $\alpha$ ) of the 10 -item scale increased to 0.936 .

Conclusion These results showed that the 10 -item version of the scale appeared to be more valid than the 17 -item version. We suggest that the 10-item web-based board game behavioral scale is a useful tool for assessing the risk of pathologic web-based board gaming.
\end{abstract}

Psychiatry Investig 2020;17(2):106-113

Key Words Web-based board game, Exploratory factor analysis, Reliability, Validity.

\section{INTRODUCTION}

Web-based board games are real-time board games that are played using a web browser. ${ }^{1}$ Well-known board games including chess, backgammon, monopoly, and dice or poker card games are played online. For example, in Korea, a poker card game called "flower cards" is played using a web browser. However, the characteristics of money differ between web-based board games and internet-based gambling (virtual vs. real). Web-based board gamers use virtual money (i.e., not real money), which can be purchased on the game websites. In Korea, the government has strictly limited the amount of virtual money (up to $\$ 500$ a month) that users can purchase for playing online board games across the country. ${ }^{2}$ However, in some in-

Received: July 15, 2019 Revised: September 2, 2019

Accepted: October 21, 2019

$\triangle$ Correspondence: Doug Hyun Han, MD, PhD

Department of Psychiatry, Chung Ang University Hospital, 102 Heukseok-ro, Dongjak-gu, Seoul 06973, Republic of Korea

Tel: +82-2-6299-3132, Fax: +82-2-825-8474, E-mail: hduk70@gmail.com

(c) This is an Open Access article distributed under the terms of the Creative Commons Attribution Non-Commercial License (https://creativecommons.org/licenses/bync/4.0) which permits unrestricted non-commercial use, distribution, and reproduction in any medium, provided the original work is properly cited. stances, a small number of online board gamers have illegally converted virtual money into real money through illegal websites. ${ }^{3}$ Internet-based gamblers use real money, typically through credit card transactions. In Korea, internet-based gambling is illegal. Korean internet-based gamblers access illegal gambling sites to bet real money using their personal computers at home.

In our previous study ${ }^{4}$ we compared the characteristics of online board gamers with those of online and offline gamblers; we found that online board gamers have more positive reasons for gaming than internet-based gamblers and offline gamblers. In addition, the behavior of online board gamers was less risky, in terms of gambling patterns, compared to that of offline gamblers, and less introverted, compared to that of internet-based gamblers. ${ }^{5,6}$ Based on these results, we suggested that monitoring online board gamers may be an efficient approach to curb illegal gambling.

The first step in the monitoring of online board gamers is screening for risky behaviors. The characteristics of online board gamers, which we referred to as gambling behaviors and psychological status, include impulsivity, mood, and attention. ${ }^{7,8}$ Online gamblers are thought to have an introverted personality and depressed mood. ${ }^{8}$ Based on an online survey, which in- 
cluded 10,838 internet-based poker players, Gainsbury et al. ${ }^{9}$ reported that internet-based poker players showed a greater tendency to "chase their losses" (i.e., seek to recoup lost bets by increasing their subsequent bets) than were offline gamblers. In a review of internet-based poker, factors predictive of excessive internet-based poker playing are suggested to be negative emotions, irrational beliefs, and impulsivity. ${ }^{10}$ In addition, internet-based gambling is associated with less verbal communication and fewer consequences regarding a lack of emotional control. ${ }^{11}$

Therefore, in this study, three measures including the Center for Epidemiological Studies-Depression Scale, ${ }^{12}$ Gambling Abstinence Self-efficacy Scale, ${ }^{13}$ and Korean Gambling Behavior Scale ${ }^{14}$ were used to evaluate the emotional state of the participants, the result of the games, and the defense effect of the online gambler, respectively. Based on previous studies, we aimed to develop and verify a web-based board game behavioral scale using a sample of 300 Korean online board gamers to assess the risk of problematic web-based board gaming.

\section{METHODS}

\section{Participant recruitment}

Invitations to participate in the current study were sent via e-mail to registered members, aged 20 years and older by an online research company (Embrain ${ }^{\circledR}$, Seoul, Korea). Each participant received $\$ 20$ as compensation when they completed the survey. A total of 200,000 invitations were sent to registered members between September 1, 2018 and September 11, 2018. By the end of the study, 6,137 of them opened the e-mail, 4,132 began the survey, and 425 completed the survey. Among these
425 individuals (172 excessive online board gamers and 253 general online board gamers), data from 300 participants (150 excessive online board gamers and 150 general online board gamers) were randomly collected (Figure 1). The inclusion criteria for excessive online board gamers were as follows: 1) engagement with a web-based board game (i.e., flower cards, poker, or Texas holdem) for more than 4 days/week, with a period of more than 1 year spent on a legal online site and 2) the presence of at least one of the behavioral symptoms, including anxiety, agitation, and anger, in a participant when he/she stopped playing a web-based board game, increased amount of money placed on bets, and failed to stop gaming. The inclusion criteria for general online board gamers were as follows: 1) engagement with a web-based board game for less than 4 days/week; and 2) absence of any of the behavioral symptoms, including anxiety, agitation, and anger in a participant when he/she stopped gambling, increased the amount of money placed on bets, and failed to stop gambling.

\section{Item selection for web-based board game behavioral scale and verification}

The web-based board game behavioral scale (WBGS) was designed to measure the self-reported risk of problematic online board gaming as reported by gamers. Seventeen items were rated using a 4-point Likert scale, with 1 representing no problem at all and 4 representing a severe problem. To organize the items of web-based board game behavioral scale, we used data from 100 online board gamers (male vs. female $=80$ vs. 20; mean age $=38.3 \pm 8.6$ years) and 100 healthy controls (male vs. female $=80$ vs. 20 ; mean age $=35.2 \pm 7.2$ years) in a previous study on online board gamers (Figure 1). ${ }^{4}$ Based on a factor analysis

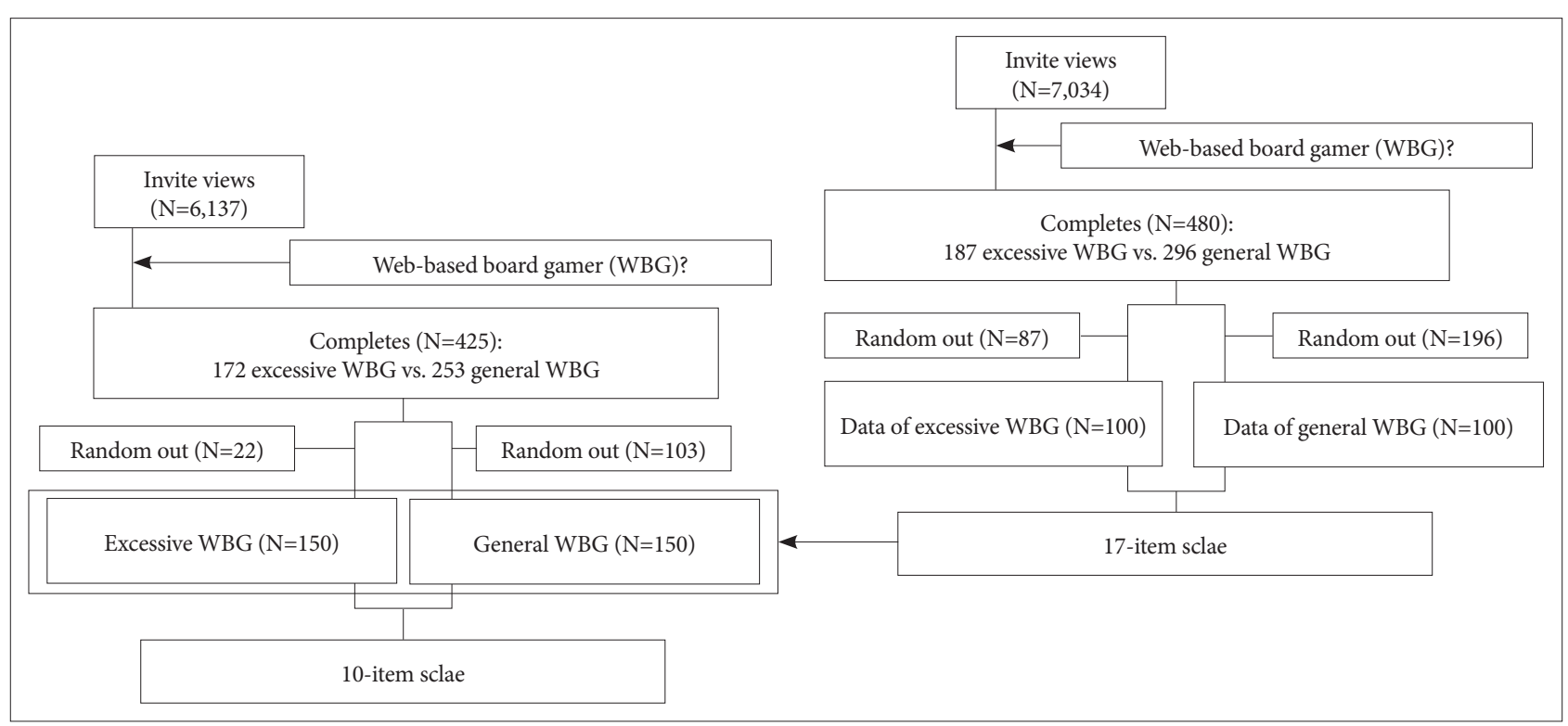

Figure 1. Algorithm of the participant sampling method and item selection. 
of the three scales, including the Gambling Abstinence Selfefficacy Scale (GASS), ${ }^{13}$ Korean Gambling Behavior Scale (KGBS), ${ }^{15,16}$ and Center for Epidemiological Studies-Depression Scale (CES-D), ${ }^{12,17} 17$ items with a Cronbach's a value of 0.70 or higher were extracted. ${ }^{18,19}$

The GASS is thought to assess the confidence of gamblers when they quit gambling. ${ }^{13}$ It consists of 21 items with a sixpoint Likert scale as well as good internal (Cronbach $\alpha=0.93$ ) and retest reliability (intraclass correlation $=0.86) .{ }^{13}$ With both low and high factors, the KGBS was developed to assess the interest (low factors) and high-risk behaviors (high factors) in gambling. It consists of 20 items with a four-point Likert scale and has good internal reliability (Cronbach $0.90-0.91) .{ }^{15,16}$ CES$\mathrm{D}$ is widely used to assess depressive symptoms in the general population. It consists of 10 items with a four-point Likert scale and has good validity (convergent validity $=0.91$, Divergent validity=0.89).

Among the 17 items included in WBGS, 6 items were from GASS [(1) I want to play web board games suddenly sometimes, (2) I play web board games when I am sad, (3) I play web board games when I worry about interpersonal relationships with others, (4) I think about web board games when I bet with someone, (6) I tend to play web board games because I want to continue winning, and (7) I tend to play web board games to overturn all the games that I have lost so far], 6 items were from KGBS [(5) I play web board games more than most people, (8) I play web board games to make up for the game money I have lost from web board gaming, (14) I hardly ever think about playing web board games, (15) I play web board games for leisure, (16) I hide the fact that I am addicted to web board games, and (17) I do not communicate with my family or participate in social activities as much because of web board games], and 5 items were from CES-D [(9) I usually have difficulty concentrating whenever I do something, (10) I often get tired whenever I do something, (11) I am usually happy, (12) I usually enjoy life, and (13) I suddenly tend to cry].

For the 17 original items, confirmatory factor analysis (CFA) was performed to estimate acceptable model fit for one-latent factor solution [CFI and/or TLI $>0.90$, root mean square error of approximation (RMSEA)<0.08] using AMOS. ${ }^{20}$ However, the data did not meet these criteria: $\mathrm{CFI}=0.754$, TLI $=0.719$, $\mathrm{RMSEA}=0.151$. Since the original 17 items did not meet the one-factor latent structure, a series of additional exploratory factor analyses (EFA) was used to identify and determine the best factor structure of the scale. After considering the results of factor analysis and the content validity of the items, we extracted 10 items from the 17 original items. Total scores of the 10 items on WBGS were compared between the high-risk group and low-moderate risk group using the independent $t$ test (Figure 1).

\section{Statistical analysis}

Demographic characteristics of participants were analyzed using the independent t-test and chi-square test. The factor analysis for the items of WBGS included principal axis factoring, oblique rotation, and sub-factor analysis (internal consistency coefficient, Cronbach's $\alpha$ ).

A k-means cluster analysis was performed to segregate all the participants into either the risk-user group or general-user group. In addition, k-means cluster analysis was performed to segregate risk-user group into high-risk group and lowmoderate risk group. Receiver operating characteristic (ROC) curves were used for calculating sensitivity, specificity, and area under the curve (AUC) and to determine the cut-off points for the individuals of risk-user group with problematic web-based board gaming. The best cut-off point was considered as the one with the highest values of sensitivity+specificity. All the data analyses were carried out using SPSS ver. 21.0 (IBM Corp., Armonk, NY, USA).

\section{Ethics statement}

The study protocol was approved by the Institutional Review Board of the Chung Ang University (IRB Number: 1041078201901-HRBM-002-01). Informed consent was obtained from the participants and confirmed by the board.

\section{RESULTS}

\section{Demographic and web-based board gaming characteristics}

The mean age and sex ratio (male:female) of the 300 participants were $38.7 \pm 8.4$ years and 80:20, respectively. Most participants had an undergraduate degree, a job, and an annual income of \$20,000-40,000. There were no significant differences in age, sex ratio, marital state, education level, and job status between excessive users and general users. However, the income level of excessive users was higher than that of general users (Table 1).

The mean time of online board gaming was $2.5 \pm 2.2 \mathrm{~h} / \mathrm{ses}-$ sion and the mean amount of money spent for a web-based board game/session was $\$ 12.9 \pm 38.9$. In addition, $17.7 \%$ of the gamers in the current study had a history of interpersonal problems in their family, school, or workplace. Seventy-eight percent of excessive users played web-based board games every day and $66.0 \%$ of general users played $2-3$ sessions of webbased board games per week. Forty-one percentage of excessive users played web-based board games for 20-30 h/week and $90.7 \%$ of general users played web-based board games for less than $10 \mathrm{~h} /$ week (Table 2). 


\section{Reliability and validity of the web-based board game behavioral scale}

The internal consistency of the WBGS was high (Cronbach's $\alpha=0.89$ ). Test-retest reliability of 17 item WBGS was $r=0.77$ $(\mathrm{p}<0.001)$. Relatively high criterion-related validity $(\mathrm{t}=16.1, \mathrm{p}<$ 0.001 ) of the 17-item WBGS was observed when the WBGS total scores between the high-risk group (44.9 \pm 7.6$)$ and lowrisk group $(32.3 \pm 5.7)$ were compared.

\section{Factor analysis for the items of the web-based board game behavioral scale}

The acquired data was acceptable based on factor analysis (Kaiser-Meyer-Olkin Measure of Sampling Adequacy $=0.918$; Bartlett's Test of Sphericity, $\chi^{2}=3351.714, \mathrm{df}=136, \mathrm{p}<0.001$ ). Explanatory factor analysis revealed that the 17 items of WBGS could be characterized as three factors. Among the 12 items of factor 1 , the factor loading values were acceptable for all the

Table 1. Demographic characteristics

\begin{tabular}{|c|c|c|c|c|}
\hline & Total & Excessive users & General users & Statistics \\
\hline Age & $38.7 \pm 8.4$ & $38.0 \pm 8.5$ & $39.4 \pm 8.2$ & $\mathrm{t}=1.38, \mathrm{p}=0.17$ \\
\hline Sex (male/female) (\%) & $240 / 60(80.0 / 20.0)$ & $120 / 30(80.0 / 20.0)$ & $120 / 30(80.0 / 20.0)$ & \\
\hline Marriage (married/single) (\%) & $178 / 122(59.3 / 40.7)$ & $88 / 62(58.7 / 41.3)$ & $90 / 60(60.0 / 40.0)$ & $\chi^{2}=0.01, \mathrm{p}=0.90$ \\
\hline Education (\%) & & & & $\chi^{2}=0.43, p=0.72$ \\
\hline High school & $46(15.3)$ & $23(15.3)$ & $23(15.3)$ & \\
\hline College/University & $231(77.1)$ & $117(78.0)$ & $114(76.0)$ & \\
\hline Graduate & $23(7.6)$ & $10(6.7)$ & $13(8.7)$ & \\
\hline Job (\%) & & & & $\chi^{2}=0.03, p=0.87$ \\
\hline Students & $16(5.3)$ & $9(6.0)$ & $7(4.6)$ & \\
\hline Officers & $177(59.0)$ & $85(56.7)$ & $92(61.3)$ & \\
\hline Service & $36(12.0)$ & $21(14.0)$ & $15(10.0)$ & \\
\hline Owners & $52(17.3)$ & $28(18.7)$ & $24(16.0)$ & \\
\hline Non-job & $19(6.4)$ & $7(4.6)$ & $12(8.0)$ & \\
\hline Income (\%) & & & & $\chi^{2}=5.99, p=0.01$ \\
\hline$<\$ 20,000$ & $21(7.0)$ & $8(8.0)$ & $13(8.7)$ & \\
\hline$\$ 20,000-39,999$ & $103(34.4)$ & $44(29.3)$ & $59(39.3)$ & \\
\hline$\$ 40,000-59,999$ & $96(32.0)$ & $51(34.4)$ & $45(30.0)$ & \\
\hline$>\$ 60,000$ & $80(26.6)$ & $47(31.3)$ & $33(22.0)$ & \\
\hline
\end{tabular}

Table 2. Web board gaming pattern

\begin{tabular}{|c|c|c|c|c|}
\hline & Total & Excessive users & General users & Statistics \\
\hline Frequency (\%) & & & & $\chi^{2}=244.3, p<0.01$ \\
\hline Everyday & $117(39.0)$ & $117(78.0)$ & $0(0.0)$ & \\
\hline 4-5/week & $33(11.0)$ & $33(22.0)$ & $0(0.0)$ & \\
\hline 2-3/week & $99(33.0)$ & $0(0.0)$ & $99(66.0)$ & \\
\hline 1/week & $42(14.0)$ & $0(0.0)$ & $42(28.0)$ & \\
\hline $1 /$ month & $9(3.0)$ & $0(0.0)$ & $9(6.0)$ & \\
\hline Play time (hours/week) (\%) & & & & $\chi^{2}=249.4, p<0.01$ \\
\hline$<10$ & $136(45.3)$ & $0(0.0)$ & $136(90.7)$ & \\
\hline $10-20$ & $14(4.7)$ & $0(0.0)$ & $14(9.3)$ & \\
\hline $21-30$ & $62(20.7)$ & $62(41.3)$ & $0(0.0)$ & \\
\hline $31-40$ & $45(15.0)$ & $45(30.0)$ & $0(0.0)$ & \\
\hline$>41$ & $43(14.3)$ & $43(28.7)$ & $0(0.0)$ & \\
\hline Play time (hours/session) & $2.5 \pm 2.2$ & $3.4 \pm 2.2$ & $1.5 \pm 1.7$ & $\mathrm{t}=8.42, \mathrm{p}<0.01$ \\
\hline Spent money (\$/session) & $12.9 \pm 38.9$ & $24.6 \pm 52.4$ & $1.2 \pm 3.3$ & $\mathrm{t}=8.45, \mathrm{p}<0.01$ \\
\hline Social problems (yes/no) & $53 / 247(17.7 / 82.3)$ & $53 / 97(35.3 / 64.7)$ & $0 / 150(0 / 150)$ & $\chi^{2}=64.2, p<0.01$ \\
\hline
\end{tabular}


items except for items 9 and 10 (factor loading<0.4). In a second analysis, all 10 items were characterized as one factor. Factor loading scores were high (0.639-0.841). After removing 7 items, Cronbach's a value increased from 0.89 (17-item WBGS) to 0.94 (10-item WBGS) (Table 3).

\section{Cluster analysis of the study sample}

In the k-means cluster analysis of the participants (300), the highest total 10-item WBGS score (40) in the risk-user group and the lowest total 10-item WBGS score (10) in the generaluser group were selected as initial seeds (centroids of respective groups). Final centroid and mean \pm standard deviation (SD) of the total 10-item WBGS score of the risk-user group were 29 and $29.47 \pm 3.76$, respectively. The corresponding values of the general-user group were 17 and 17.28 \pm 4.27 , respectively. The final Euclidean distance between the two groups was 12.189. After k-means cluster analysis, the 300 participants were classified into a risk-user group (119) and general-user group (181).

In the k-means cluster analysis of the risk-user group (119), the highest total 10-item WBGS score (40) in the high-risk group and the lowest total 10-item WBGS score (24) in the low-moderate risk group were selected as initial seeds (cen- troids of respective groups). Final centroid and mean \pm SD of the total 10-item WBGS score of the high-risk group were 34 and 33.67 \pm 2.04 , respectively. The corresponding values of the low-moderate risk group were 27 and $27.09 \pm 1.99$, respectively. The final Euclidean distance between the two groups was 6.582. After k-means cluster analysis, the 119 participants were classified into a high-risk group (43) and low-moderate risk group (78).

\section{Receiver operating characteristic curve analysis of the web-based board game behavioral scale score}

Among the 300 participants, the cut-off 10 -item WBGS score (total) of the risk-user group was set at 22 with an AUC of 0.916 (95\% CI: 0.884-0.947) (Figure 2). As shown in Table 4, the sensitivity and specificity values were the highest for the 10-item WBGS scores of 21.5 and 22.5, respectively.

Among the individuals in the risk-user group (119), the cutoff WBGS score (total) of the high-risk group was set at 31 with an AUC of 0.864 (95\% CI: 0.797-0.911) (Figure 2). As shown in Table 4, the sensitivity and specificity values were the highest for the 10-item WBGS score of 30.5 and 31.5, respectively.

Table 3. Factor loading for problematic web board gaming: 17 items vs. 10 items

\begin{tabular}{|c|c|c|c|c|c|}
\hline \multirow{2}{*}{$\begin{array}{l}\text { Items } \\
\text { No. }\end{array}$} & & \multicolumn{3}{|c|}{17 items } & \multirow[t]{2}{*}{10 items } \\
\hline & & Factor 1 & Factor 2 & Factor 3 & \\
\hline 1 & I want to play web board games suddenly sometimes & 0.622 & & & 0.639 \\
\hline 2 & I play web board games when I am sad & 0.788 & & & 0.765 \\
\hline 3 & I play web board games when I worry about interpersonal relationships with others. & 0.803 & & & 0.772 \\
\hline 4 & I think about web board games when I bet with someone & 0.750 & & & 0.754 \\
\hline 5 & I play web board games more than most people & 0.807 & & & 0.822 \\
\hline 6 & I tend to play web board games because I want to continue winning & 0.805 & & & 0.836 \\
\hline 7 & I tend to play web board games to overturn all the games that I have lost so far & 0.818 & & & 0.841 \\
\hline 8 & $\begin{array}{l}\text { I play web board games to make up for the game money I have lost from web board } \\
\text { gaming }\end{array}$ & 0.810 & & & 0.829 \\
\hline 9 & I usually have difficulty concentrating whenever I do something & 0.354 & & & - \\
\hline 10 & I often get tired whenever I do something & 0.351 & & & - \\
\hline 11 & I am usually happy & & 0.897 & & - \\
\hline 12 & I usually enjoy life & & 0.936 & & - \\
\hline 13 & I suddenly tend to cry & & & -0.341 & - \\
\hline 14 & I hardly ever think about playing web board games & & & 0.582 & - \\
\hline 15 & I play web board games for leisure & & & -0.532 & - \\
\hline 16 & I hide the fact that I am addicted to web board games & 0.716 & & & 0.687 \\
\hline 17 & $\begin{array}{l}\text { I do not communicate with my family or participate in social activities as much } \\
\text { because of web board games }\end{array}$ & 0.775 & & & 0.748 \\
\hline \multicolumn{2}{|r|}{ Eigen value } & 7.60 & 1.85 & 0.89 & 5.96 \\
\hline \multicolumn{2}{|c|}{ Variance extracted } & 44.7 & 10.9 & 5.22 & 59.6 \\
\hline
\end{tabular}




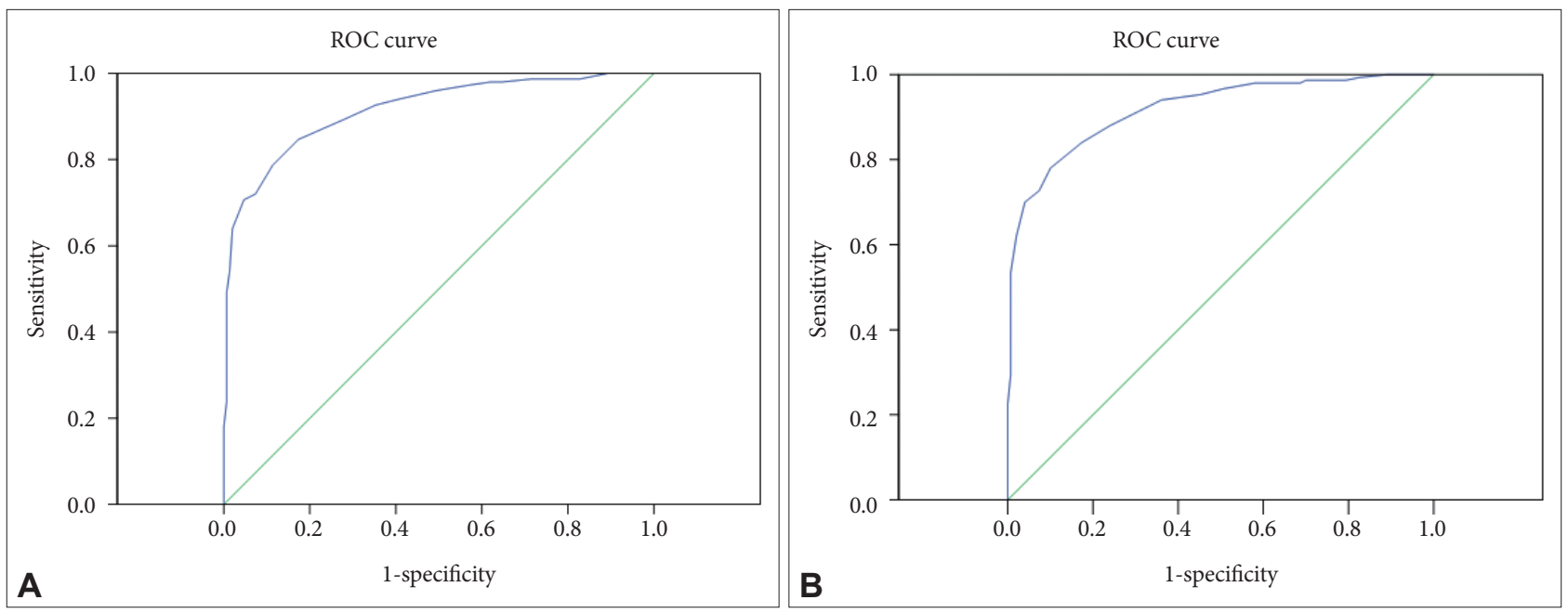

Figure 2. Receiver operating characteristic (ROC) curves for the low- and high-risk web-based board game groups. A: Risk web-based board game group, B: High-risk web-based board game group. WBGS: web-based board game behavioral scale.

Table 4. Sensitivity and specificity of web board game scale in risk and high risk user groups

\begin{tabular}{|c|c|c|c|c|}
\hline Cut off value & Sensitivity & 1-specificity & Specificity & Sensitivity+specificity \\
\hline \multicolumn{5}{|c|}{ Risk group } \\
\hline 9.0000 & 1.000 & 1.000 & 0.000 & 1.000 \\
\hline \multicolumn{5}{|c|}{$\ldots$} \\
\hline 17.5000 & 0.960 & 0.493 & 0.507 & 1.467 \\
\hline 18.5000 & 0.940 & 0.407 & 0.593 & 1.533 \\
\hline 19.5000 & 0.927 & 0.353 & 0.647 & 1.573 \\
\hline 20.5000 & 0.893 & 0.280 & 0.720 & 1.613 \\
\hline 21.5000 & 0.847 & 0.173 & 0.827 & 1.673 \\
\hline 22.5000 & 0.787 & 0.113 & 0.887 & 1.673 \\
\hline 23.5000 & 0.720 & 0.073 & 0.927 & 1.647 \\
\hline 24.5000 & 0.707 & 0.047 & 0.953 & 1.660 \\
\hline 25.5000 & 0.640 & 0.020 & 0.980 & 1.620 \\
\hline \multicolumn{5}{|c|}{$\ldots$} \\
\hline 41.0000 & 0.000 & 0.000 & 1.000 & 1.000 \\
\hline \multicolumn{5}{|c|}{ High risk group } \\
\hline 23.000 & 1.000 & 1.000 & 0.000 & 1.000 \\
\hline \multicolumn{5}{|c|}{$\ldots$} \\
\hline 26.5000 & 1.000 & 0.526 & 0.474 & 1.474 \\
\hline 27.5000 & 1.000 & 0.421 & 0.579 & 1.579 \\
\hline 28.5000 & 1.000 & 0.289 & 0.711 & 1.711 \\
\hline 29.5000 & 1.000 & 0.197 & 0.803 & 1.803 \\
\hline 30.5000 & 1.000 & 0.000 & 1.000 & 2.000 \\
\hline 31.5000 & 0.800 & 0.000 & 1.000 & 1.860 \\
\hline 32.5000 & 0.628 & 0.000 & 1.000 & 1.628 \\
\hline 33.5000 & 0.535 & 0.000 & 1.000 & 1.535 \\
\hline 34.5000 & 0.326 & 0.000 & 1.000 & 1.326 \\
\hline \multicolumn{5}{|c|}{$\ldots$} \\
\hline 41.0000 & 0.000 & 0.000 & 1.000 & 1.000 \\
\hline
\end{tabular}




\section{DISCUSSION}

Using a sample of 300 web-based board game users, a behavioral assessment (WBGS) with reasonable reliability and validity was created. Our results revealed that the 10 -item WBGS had better internal consistency and validity, compared to those of the 17-item WBGS.

In the current study, the participants showed significant differences in frequency, duration, gaming time, money spent, and social problems between the excessive-user group and general-user group. Notably, the SD of the money spent was larger and the number of users with social problems due to web-based board gaming was higher in the excessive-user group than in the general-user group. These results may be associated with impulsivity. ${ }^{21,22}$ The Norwegian government helped gamblers control their impulsivity using limit-setting tools, voluntary self-exclusion, and personalized feedback. ${ }^{22}$

The internal consistency (Cronbach's $\alpha=0.89$ ) and test-retest reliability of the WBGS $(\mathrm{r}=0.77, \mathrm{p}<0.001)$ were relatively good and were accepted as reasonable. The criterion-related validity comparing the high-risk group and low-risk group was also statistically significant. However, the WBGS did not have a good fit in the CFA analysis. With that result, we suggest that the 17-items of WBGS cannot be categorized as one factor.

Based on the EFA, the 17-item WBGS had 3 factors; factor 1 (items $1-9$ and items 16-17), factor 2 (items 11-12), and factor 3 (items 13-15). Among them, all the items of the 17-item WBGS achieved acceptable factor loading scores except for items 9 and 10. However, the 10-item WBGS lacked the 5 items extracted from CES-D (items 9-13) and the items of factor 3 (items 13-15) present in the 17-item WBGS; consequently, the internal consistency was higher in the former than in the latter. The five items from CES-D were ruled out due to low factor loading or due to other dimensions associated with the factors in the current study. Many studies on gambling or internetbased games have suggested that mood status is associated with the aggravation of gambling or gaming behaviors. ${ }^{23}$ In the WBGS results, mood status assessed according to CES-D was not closely correlated with web-based board gaming. Items 14 and 15 were extracted from the low-risk factors of KGBS. The low-risk factors of KGBS were associated with the positive functions associated with gambling and disinterest in gambling. ${ }^{15,16}$ According to these results, individuals playing webbased board games may have different psychological characteristics, compared to those involved in gambling or internet gaming. The words "web-based board" were absent in the sentence extracted from CES-D. This may affect the categorization of the 17 items as three factors. Several studies have suggested that item-wording and the dimensionality in scale could affect the consequences of the survey and response of partici- pants. ${ }^{24-26}$ Moreover, Greenberg et al. ${ }^{25}$ reported that itemwording in the 10-item Rosenberg Self-Esteem Scale could affect the responses of the survey.

The cut-off point (>22) of the risk-user group for problematic web-based board gamers was obtained using an ROC curve of the 10-item WBGS. In the k-means cluster analysis, the centroid (17.28) and SD (4.27) of the risk-user group for problematic web-based board gamers was almost 22 . The cutoff point (>31) of the high-risk group for problematic webbased board gamers was obtained using an ROC curve of the 10 -item WBGS. In the k-means cluster analysis, the centroid (33.67) and SD (2.04) of high-risk group for problematic webbased board gamers was almost 31. In both the analyses, the cut-off points elucidated by ROC curves and k-means analyses coincided.

The current study had several limitations. First, because the results of the online surveys are based on a relatively small sample size and low response rate, readers should be cautious when interpreting the results. That is, there might be a small sample bias and nonresponse bias. Second, the participants in the current study were not screened by a structured clinical interview. Psychological status and comorbidities of the participants may have affected the analysis and corresponding results. Future studies should focus on the development of scales that include psychological status and comorbidities.

The current results indicate that the 10-item WBGS appeared to have greater validity than the 17-item WBGS. In addition, we suggest that the 10-item WBGS can be a useful tool for screening individuals with risk or high risk of problematic web-based board gaming behavior. Monitoring web-based board gamers may be important step for preventing illegal internet-based gambling or offline gambling. A web-based board game behavioral scale may be an effective simple screening method for assessing the behavior of excessive online game players.

\section{Acknowledgments}

This study was supported by the Game User Care Center (2018-001).

\section{Conflicts of Interest}

The authors have no potential conflicts of interest to disclose.

\section{Author Contributions}

Conceptualization: Doug Hyun Han. Data curation: Choongmeong Lee. Formal analysis: Jae Chan Jin. Funding acquisition: Sujin Bae. Investigation: Jae Jun Nam. Methodology: Doug Hyun Han. Project administration: Choongmeong Lee. Resources: Choongmeong Lee. Software: Jae Jun Nam. Supervision: Doug Hyun Han. Validation: Jae Chan Jin. Visualization: Sujin Bae. Writing_original draft: Doug Hyun Han. Writing_review \& editing: Doug Hyun Han.

\section{ORCID iDs}

Choongmeong Lee https://orcid.org/0000-0002-8905-1845

Sujin Bae https://orcid.org/0000-0002-9671-4627

Jae Jun Nam https://orcid.org/0000-0003-4842-6425 
Jae Chan Jin https://orcid.org/0000-0002-2419-5485

Doug Hyun Han https://orcid.org/0000-0002-8314-0767

\section{REFERENCES}

1. Markey K, Swanson F, Jenkins A, Jennings BJ, St Jean B, Rosenberg V, et al. The effectiveness of a web-based board game for teaching undergraduate students information literacy concepts and skills. D-Lib Mag 2008;14:1082-9873.

2. Nam HW. Web Board Game Payment Limit...Game Industry Regret. Seoul: ZDNet Korea; 2018

3. Song SY. One Million Pieces of Cash Can Go Back and Forth ... "Illegal Gambling Place' Large Game Company Web Board Game. Seoul: The Asia Business Daily; 2018.

4. Han J, Seo Y, Lee C, Han DH. Comparing the behavioral patterns and psychological characteristics of web board gamers and gamblers. Psychiatry Investig 2018;15:1181-1187.

5. Gainsbury SM. Online gambling addiction: the relationship between internet gambling and disordered gambling. Curr Addict Rep 2015;2: 185-193.

6. Müller KW, Koch A, Dickenhorst U, Beutel ME, Duven E, Wölfling K. Addressing the question of disorder-specific risk factors of internet addiction: a comparison of personality traits in patients with addictive behaviors and comorbid internet addiction. BioMed Res Int 2013;2013: 546342.

7. Barrault S, Varescon I. Online and live regular poker players: do they differ in impulsive sensation seeking and gambling practice? J Behav Addict 2016;5:41-50.

8. Pfund RA, Whelan JP, Greenburg JE, Peter SC, Wilson KK, Meyers AW. Psychological distress as an indicator of co-occurring psychopathology among treatment-seeking disordered gamblers. J Gambl Stud 2017;33:907-918.

9. Gainsbury SM, Suhonen N, Saastamoinen J. Chasing losses in online poker and casino games: characteristics and game play of internet gamblers at risk of disordered gambling. Psychiatry Res 2014;217:220-225.

10. Moreau A, Chabrol H, Chauchard E. Psychopathology of online poker players: review of literature. J Behav Addict 2016;5:155-168.

11. Eroukmanoff V, Costes JM, Tovar ML. Les joueurs de poker, a Population with a Particular Profile? Paris: Observatory of Games; 2014.

12. Cho S, Cho Y. Depressive symptoms following natural disaster in Korea: psychometric properties of the Center for Epidemiologic Studies Depression Scale. Health Qual Life Outcomes 2017;15:230.

13. David H, Nicole P, Karyn M. Self-efficacy in pathological gambling treatment outcome: development of a gambling abstinence self-efficacy scale (GASS). Int Gambl Stud 2004;4:99-108.

14. Lee SM, Kim GH, Choi YS, Le HP, Kim JN, Kim SJ. Development of Korean gambling behavior scale-H: a scale for inquiry of problematic gambling. Korean J Psychol Gen 2011;30:1053-1082.

15. National Gaming Control Commission (NGC). Available at: http:// www.ngcc.go.kr/Download. Accessed August 17, 2018.

16. Lee SM, Kim GH, Choi YS, Le HP, Kim JN, Kim SJ. Development of Korean gambling behavior scale-H: a scale for inquiry of problematic gambling. Korean J Psychol Gen 2011;30:1053-1082.

17. Radloff LS. The CES-D scale a self-report depression scale for research in the general population. Appl Psychol Meas 1977;1:385-401.

18. 18. George D, Mallery P. SPSS for Windows Step by Step: A Simple Guide and Reference. 11.0 Update (4th Ed.). Boston: Allyn \& Bacon; 2003.

19. DeVellis RF. Scale Development: Theory and Applications (2nd Edition). Los Angeles: Thousand Oaks Calif by SAGE Publications Inc; 2003.

20. O'Connor M, Lasgaard M, Shevlin M, Guldin MB. A confirmatory factor analysis of combined models of the Harvard Trauma Questionnaire and the Inventory of Complicated Grief-Revised: are we measuring complicated grief or posttraumatic stress? J Anxiety Disord 2010; 24:672-679.

21. Chauchat L, Tanguay C, Therrien R, Dufour A, Gagne S, Caron NJ. Biological monitoring of 4 antineoplastic drugs in health care workers from 2 adult hospitals: a pilot study. Can J Hosp Pharm 2019;72:56-59.

22. Auer M, Hopfgartner N, Griffiths MD. The effect of loss-limit reminders on gambling behavior: a real-world study of Norwegian gamblers. J Behav Addict 2018;7:1056-1067.

23. Jonsson J, Munck I, Volberg R, Carlbring P. GamTest: Psychometric evaluation and the role of emotions in an online self-test for gambling behavior. J Gambl Stud 2017;33:505-523.

24. Zhang X, Noor R, Savalei V. Examining the effect of reverse worded items on the factor structure of the need for cognition scale. PLoS ONE 2016;11: e0157795.

25. Greenberger E, Chen C, Dmitrieva J, Farruggia SP. Item-wording and the dimensionality of the Rosenberg Self-Esteem Scale: do they matter? Pers Individ Differ 2003;35:1241-1254.

26. Roszkowski MJ, Soven M. Shifting gears: consequences of including two negatively worded items in the middle of a positively worded questionnaire. J Assess Eval Higher Educ 2010;35:117-134. 